\title{
Coronary artery bypass graft surgery in Brazil from 2008 to 2017
}

Kalil Khalil ${ }^{1}$, Michel Sá ${ }^{2}$, Dominique Vervoort ${ }^{3}$, Leonardo Roever ${ }^{4}$, Marcos Alfredo Pires ${ }^{5}$, Jaqueline Maria Lima ${ }^{5}$, Felipe Salles ${ }^{5}$, Giovana Khalil ${ }^{5}$, Pedro Felipe Nicz ${ }^{5}$, Omar Asdrúbal Mejía $^{5}$, Arnaldo Okino ${ }^{5}$, and Ricardo Lima ${ }^{6}$

${ }^{1}$ Hospital Norte Paranaense

${ }^{2}$ Pronto Socorro Cardiológico of Pernambuco

${ }^{3}$ Johns Hopkins University Bloomberg School of Public Health

${ }^{4}$ University of São Paulo and Federal University of Uberlândia

${ }^{5}$ Affiliation not available

${ }^{6}$ Faculdade de Ciências Médicas / UPE

December 1, 2020

\begin{abstract}
Background: Brazil is an upper-middle-income country in South America with the world's sixth largest population. Little is known on the volume, outcomes and trends of coronary artery bypass grafting (CABG) in Brazil's public health system. Objective: The aim of this study was to evaluate the outcome of CABG in the public health system in from January 2008 to December 2017 through the database DATASUS. Methods: This study is based on publicly available material obtained from DATASUS, the Brazilian Ministry of Health's data processing system, on numbers of surgical procedures, death rates, length of stay, and costs. Only isolated CABG procedures were included in our study. We used the TabNet software from the DATASUS website to generate reports. Chi-square test was used to compare death rates. A p-value of $<0.05$ was considered statistically significant. Results: We identified 226,697 CABG procedures performed from January 2008 to December 2017. The overall in-hospital mortality over the 10-year period was $5.7 \%$. We observed statistically significant differences in death rates between the five Brazilian macro regions. Death rates by state ranged from $2.6 \%$ to $13.1 \%$. The national average mortality rate remained stable over the course of time. Conclusion: Over 10 years, a high volume of CABG was performed in the Brazilian Public Health System with significant differences in mortality, number of procedures, and distribution of surgeries by region. Future databases involving all centers that perform CABG and carry out risk-adjusted analysis will help improve Brazilian results, and enable policymakers to adopt appropriate health care policies for greater transparency and accountability.
\end{abstract}

\section{Hosted file}

article_FINAL.pdf available at https://authorea.com/users/380296/articles/496355-coronaryartery-bypass-graft-surgery-in-brazil-from-2008-to-2017

\section{Hosted file}

Table 1.pdf available at https://authorea.com/users/380296/articles/496355-coronary-arterybypass-graft-surgery-in-brazil-from-2008-to-2017

\section{Hosted file}

Table 2.pdf available at https://authorea.com/users/380296/articles/496355-coronary-arterybypass-graft-surgery-in-brazil-from-2008-to-2017

\section{Hosted file}


Table 3.pdf available at https://authorea.com/users/380296/articles/496355-coronary-arterybypass-graft-surgery-in-brazil-from-2008-to-2017
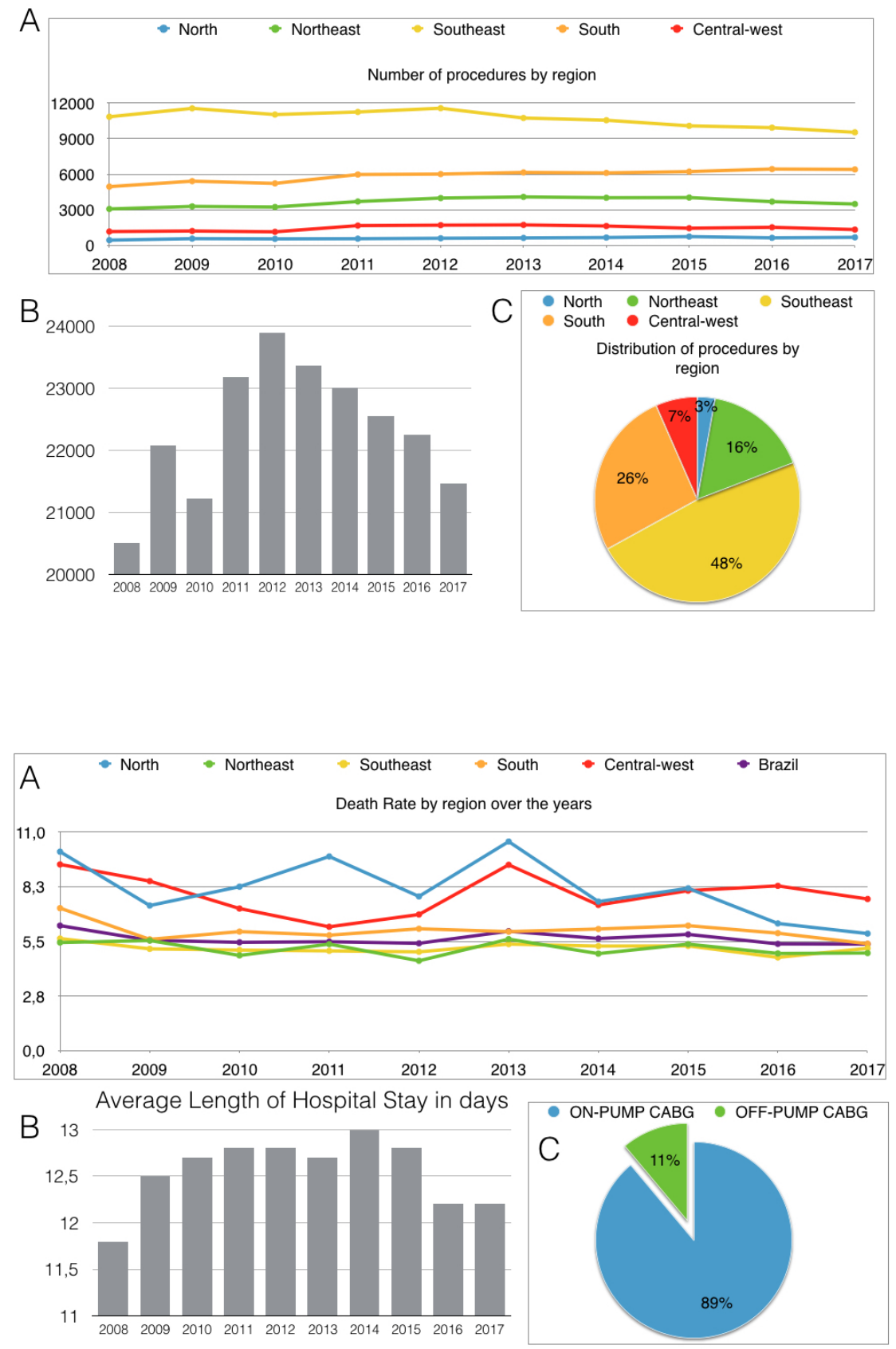

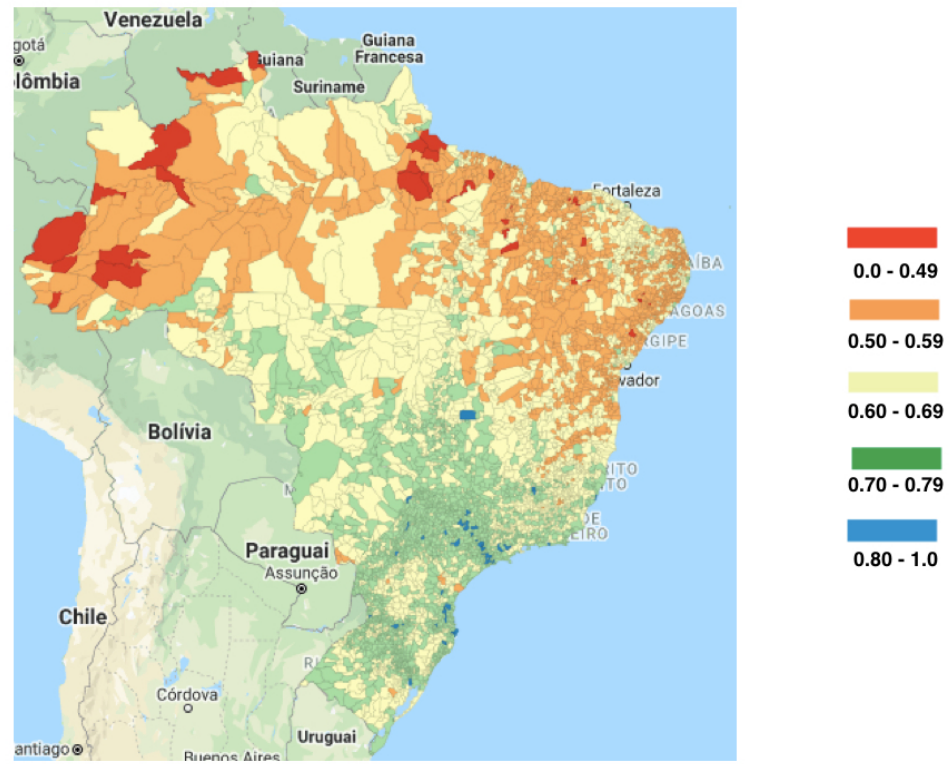

Coronary Artery Bypass Graft in Brazil from 2008 to 2017

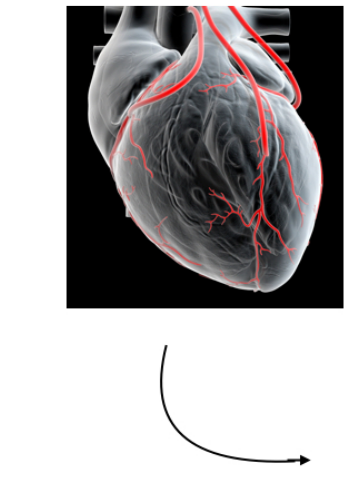

Brazilian Public Health System SUS

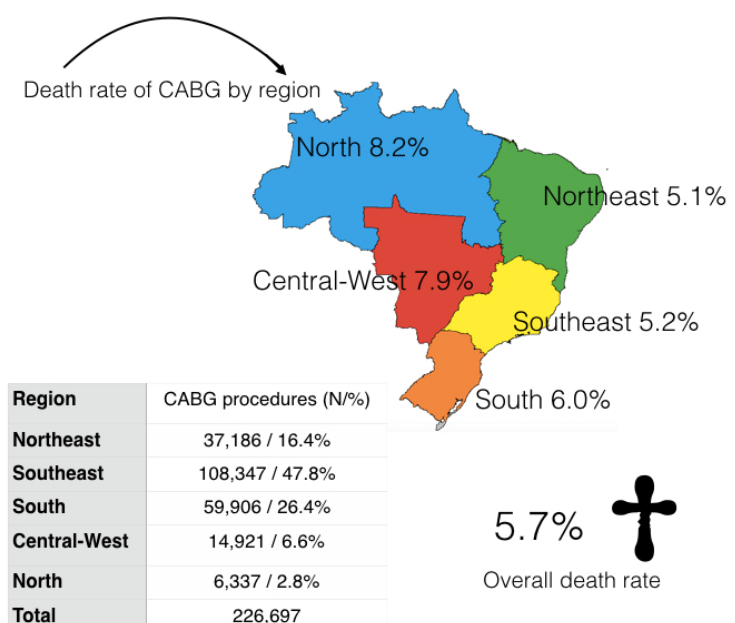



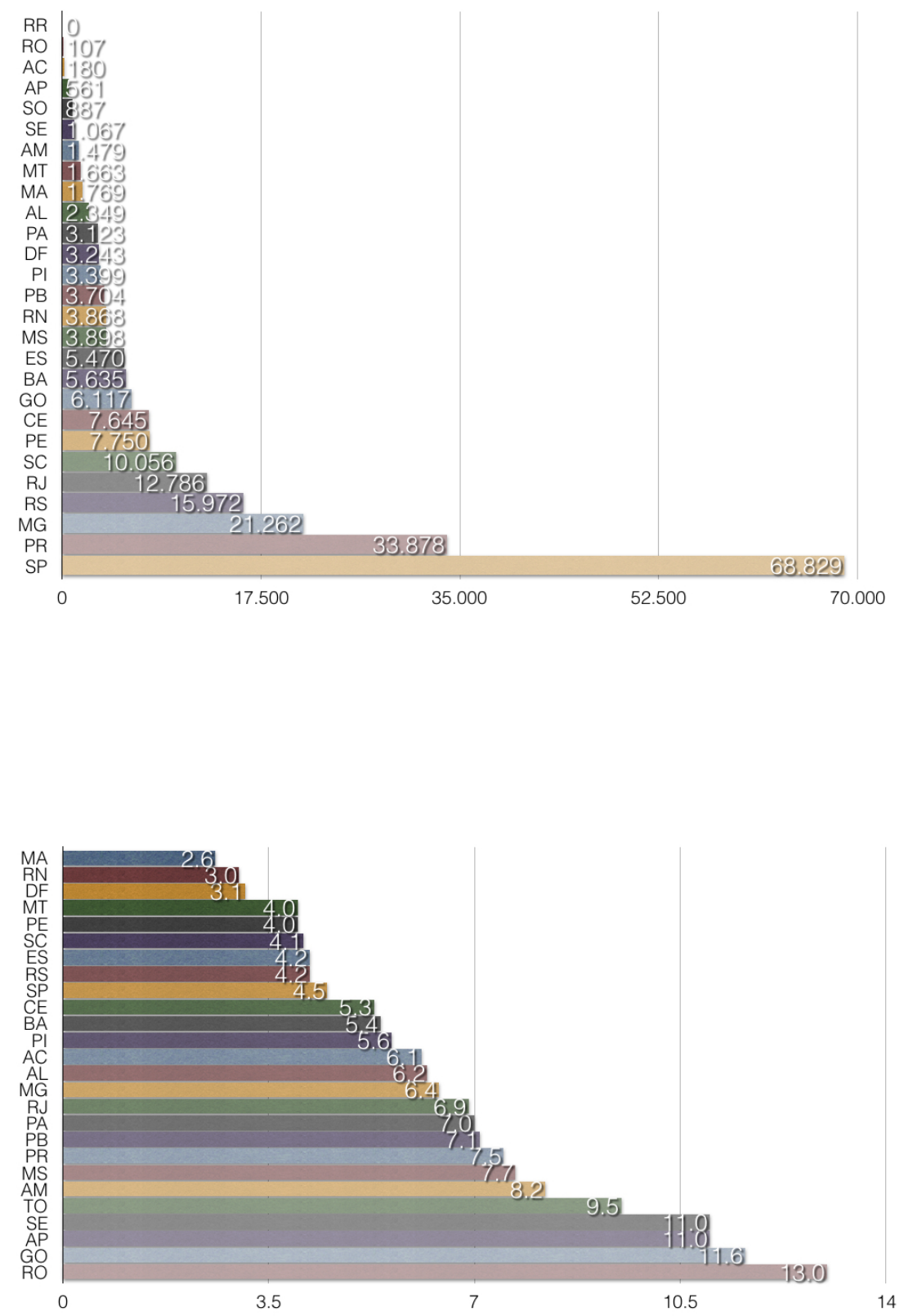


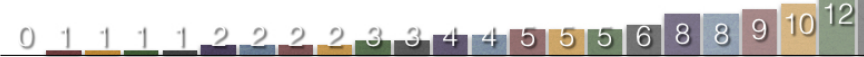

RR AC AP AM RO DF MA SE TO AL MT PA PB ES MS PI RN CE PE GO SC BA RS RJ PR MG SP 